\title{
How do patients want to learn of results of clinical trials? A survey of $|43|$ breast cancer patients
}

\author{
L Johnson, ${ }^{*, 1}$ P Barrett-Lee ${ }^{2}$, P Ellis ${ }^{3}$ and JM Bliss' on behalf of TACT Trial Management Group ${ }^{4}$ \\ 'ICR-CTSU, Section of Clinical Trials, Sir Richard Doll Building, Institute of Cancer Research, Cotswold Road, Sutton, Surrey SM2 5NG, UK; ${ }^{2}$ Velindre Cancer \\ Centre, Velindre Hospital, Whitchurch, Cardiff CFI 4 2TL, UK; ${ }^{3}$ Department of Medical Oncology, Thomas Guy House, Guy's Hospital, St Thomas Street, \\ London SEI 9RT, UK
}

\begin{abstract}
Questionnaires were circulated to UK patients and health care professionals (HCPs) participating in the Taxotere as Adjuvant ChemoTherapy (TACT) trial in autumn 2004 asking if and how trial results, when available, should be conveyed to patients. A total of I43| (37\% of surviving UK TACT patients) returned questionnaires. In all, 30 (2\%) patients did not want results. In all, 554 (40\%) patients preferred to receive them via their hospital; 664 (47\%) preferred results posted directly to their home, I77 (I 3\%) preferred a letter providing a telephone number to request results. Six hundred and twelve patients thought results should come directly from the trials office. One hundred and seventy-six HCPs from 89 UK centres (86\%) returned questionnaires. In all, I69 out of I76 patients (96\%) thought results should be written in lay terms for patients. Seventy (4l\%) preferred patients to receive results via their hospital; 64 (38\%) preferred a letter providing a telephone number to request results, and 32 (19\%) preferred results posted directly to patients. Thirty-one HCPs (18\%) thought results to patients should come directly from the trials office. A total of 868 (61\%) patients thought next of kin of deceased patients should receive results, 543 (38\%) did not; 47 (27\%) HCPs thought they should; I 8 (68\%) did not.
\end{abstract}

British Journal of Cancer (2008) 98, 34-38. doi:10.1038/sj.bjc.6604II9 www.bjcancer.com

Published online 4 December 2007

(c) 2008 Cancer Research UK

Keywords: trial results; participating patients; lay terms

The view that researchers have an obligation (Fernandez et al, 2003) to provide results of clinical trials to those who participate in them has reached mainstream thinking, with professional medical bodies (Royal College of Physicians, 1990) supporting this approach. However, within the UK, recently updated national guidelines on information sheets for trial participants (www.nres. npsa.nhs.uk) advise caution in disseminating results to participants, an approach which is justified by the mixed findings from several studies (Snowdon et al, 1998; Richards et al, 2003; Dixon-Woods et al, 2006). The guidelines' distinction between 'broad scientific results of a trial' and 'results of relevance to the individual' is welcomed, as the broad scientific results may need to be presented to participants in the context of (possibly) differing results from similar trials, which taken individually may be confusing or inconclusive, and normally have no bearing on the patients' future clinical care.

For cancer treatment trials in patients with early disease, a lapse of several years from trial entry to availability of results means that unexpected contact to convey results could cause undue alarm.

\footnotetext{
*Correspondence: L Johnson; E-mail: Lindsay.Johnson@icr.ac.uk

${ }^{4}$ TACT TMG: J Banerij, P Barrett-Lee, JM Bliss, D Bloomfield, AM Brunt, D Cameron, R Coleman, I Devine, P Ellis, D Dodwell, H Earl, E Graham, E Hall, A Harnett, P Hopwood, S Houston, L Johnson, S Johnston, A Jones, H Moore, C Peckitt, T Perren, C Poole, I Smith, C Twelves, $M$ Verrill, A Wardley, J Yarnold.

Received 17 July 2007; revised | November 2007; accepted 2 November 2007; published online 4 December 2007
}

Two further studies (Partridge et al, 2004, 2005) both show that the majority of cancer patients would like to receive results, but provide conflicting data on whether patients want results conveyed by their doctor or they are comfortable receiving them by post. For trials with survival as an endpoint, the issue of how, when and whether to disseminate results to the next of kin of those who have died has not been fully explored.

In this paper, we report an attempt to evaluate whether patients who took part in the Taxotere as Adjuvant ChemoTherapy (TACT) trial (Barrett-Lee et al, 2002) wish to be informed of the trial results when they become known. We sought preferences relating to the possible practical mechanisms for distributing them to participating patients, and in the case where the patient has subsequently died, the extent to which participants supported the idea that their next of kin should receive the results. We compared the views of participating patients with those of the health care professionals involved with the TACT trial, that is those most likely to convey trial results to patients, who will appreciate the scientific context, and practical considerations which may not be obvious to patients.

Taxotere as Adjuvant ChemoTherapy is a large multicentre trial in patients with early breast cancer, which recruited 4124 women from 103 participating UK hospitals, and 38 from 1 Belgian centre between January 2001 and June 2003, and compares an anthracycline-taxane chemotherapy sequence with standard UK anthracycline chemotherapy. Treatment was scheduled to last approximately 6 months. Long term follow-up will allow comparison of the rates of disease relapse and death between treatment groups. A survey of the UK patients was conducted in the autumn of 2004, well before clinical outcome data was known. Median time 
since randomisation was 28 months (range $=15-44$ months), and $282(7 \%)$ had died. The timing aimed to capture patients' views after treatment was completed and normal day to day activities were resumed, at a time when the rate of disease relapse and death remained low and ahead of the attainment of the trial's results.

\section{AIM}

We aimed to find out from trial patients whether they wanted to receive trial results written in lay terms when they are available, and how they considered they wanted to receive them. We compare their preferences with those expressed by health care professionals (oncologists and nurses) who had participated in the TACT trial.

\section{METHOD}

Following ethics approval from the South East Multi-Centre Research Ethic Committee, a patient newsletter accompanied by a patient questionnaire was sent to UK hospitals to distribute to surviving TACT patients. The newsletter aimed to remind patients that follow-up continued, and explained why the trial had so far not produced any published results. Health Care Professionals (HCPs) either posted these directly to trial patients, or distributed them in the hospital clinic. Health care professionals could withhold the newsletter and questionnaire from individuals or groups of patients if they considered them inappropriate for example, those receiving palliative care. The exact number of questionnaires distributed is not known, however feedback from hospitals following an earlier patient newsletter suggests approximately 3000 of a possible 3842 were distributed.

Explanation of advantages and disadvantages of 3 methods of distributing results

Results posted as soon as they are available

Advantages: Get results quickly.

Disadvantages: Results arrive unexpectedly.

Patients could be distressed by sudden intrusion, especially if results are different from what they expected.

Patient's doctor or nurse not on hand to answer questions.

If researchers post the results to patients' home addresses (Hospitals need to disclose this

confidential information and address lists quickly become out of date).

Letter saying results are available, with a phone number to call for a copy

Advantages: Patients can choose timing of when to get results.

Patients are expecting results to arrive.

Disadvantages: Need to make a phone call to an information helpline.

Patient's doctor or nurse not on hand to answer questions.

If researchers post the letter to patients' home addresses (Hospitals need to disclose this.

confidential information and address lists quickly become out of date).

Results given at a hospital visit

Advantages: Doctor or nurse on hand to explain results and answer questions straight away.

Disadvantages: Could be a delay in getting results.

If the results affect individual patient's care, this can be discussed straight away.

Questionnaire:

Please tick one box below to show which of the four options you, personally, would like:

1. I prefer results to be posted to me as soon as they are available

2. I prefer a letter telling me when results are available, with a phone number to call for a copy

3. I prefer my hospital doctor or nurse to tell me the results at a clinic visit

4. I do not want to know the results

If you have ticked option 1 or 2, please choose one of the following two options by ticking one box My home address should be made available to the Institute of Cancer Research so they can post results to me directly

My home address is confidential and the Institute of Cancer Research should send results to my hospital, for the hospital to post them to me

Unfortunately some patients will have died before the results become available. Do you think the next of kin of such patients should be told of the results?

Yes $\square \quad$ No $\square$

please answer the question below

If the patient previously decided they did not want the results, should their next of kin receive them? Yes $\square \quad$ No $\square$

What is your age group? Please tick one box 18-39 $\square \quad 40-59 \quad \square 60-69 \square \quad 70$ or over

What county do you live in? (e.g. Yorkshire)

Would you like to complete questionnaires in the future about patients' attitudes and preferences?

Yes, any time $\square \quad$ Yes, but no more than one $\square \quad$ No $\square$

Figure I Patient questionnaire. 
The questionnaire described three methods of distributing results, and explained the advantages and disadvantages of each, as perceived by the researchers at the Clinical Trials \& Statistics Unit at the Institute of Cancer Research (ICR-CTSU). Patients were then asked if they wanted results written in lay terms, and if so, which of the three methods they preferred (Figure 1). Patients were also asked about the theoretical scenario of whether and how to convey results to the next of kin of patients who had died. Information on patient age group and geographical region was collected to allow any age or regional trends to be identified. A similar survey of participating HCPs conducted simultaneously asked whether and how results should be distributed to patients, and offered the same three options. (Figure 2). Additional advantages and disadvantages, which were of no relevance to patients, were included for HCPs, which highlighted the impact of the different distribution methods on working practices. All respondents who preferred patients to receive results by post were also asked if, in principal, they thought ICR-CTSU as the coordinating

The following (additional) advantages and disadvantages were presented to HCPs:

Results posted as soon as they are available

Disadvantages: Clinicians and nurses could be deluged with patients' questions

Letter saying results are available, with a phone number to call for a copy

Advantages: Results only go to patients who want them, and at a time of their choosing (altered wording only)

Disadvantages: Clinicians and nurses do not know which patients have received results and when, and may not be available to answer questions

Clinicians and nurses could be deluged with patients' questions

Results given at a hospital visit

Disadvantages: Resources may not be available for extra appointments to explain results Logistically difficult to monitor and/ or recall patients Many patients could be followed up at other hospitals or GPs, and may not get the results for many months, if at all

Questionnaire:

\begin{tabular}{|lll}
\hline Should trial results be written in lay terms and given to participating patients? & Yes $\square$ \\
\hline
\end{tabular}

Should the TACT trial results be given to patients:

\begin{tabular}{|c|c|}
\hline By ICR-CTSU * & By the patients' hospital \\
\hline$\nabla$ & $\downarrow$ \\
\hline $\begin{array}{l}\text { Should ICR-CTSU send: } \\
\text { the results directly to the patients } \\
\text { home address* } \\
\text { or } \\
\text { a letter to the patients home } \\
\text { address saying, results are } \\
\text { available, with a central national } \\
\text { helpline phone number to } \\
\text { request them if they wish* } \\
\text { * The Institute of Cancer Research does } \\
\text { not normally collect patients' addresses, } \\
\text { and does not have the home addresses of } \\
\text { TACT trial patients. }\end{array}$ & $\begin{array}{l}\text { Should ICR-CTSU send: } \\
\text { results for hospitals to forward on to patients' home addresses } \\
\text { or } \\
\text { a letter for hospitals to forward on to patients' home addresses } \\
\text { saying the results are available, with a central national helpline } \\
\text { phone number to request them if they wish } \\
\text { or should they be: } \\
\text { given to patients by the clinician or nurse at their next hospital } \\
\text { visit } \\
\text { or should: } \\
\text { patients be recalled for an appointment to discuss the results } \\
\text { with the clinician or nurse }\end{array}$ \\
\hline
\end{tabular}

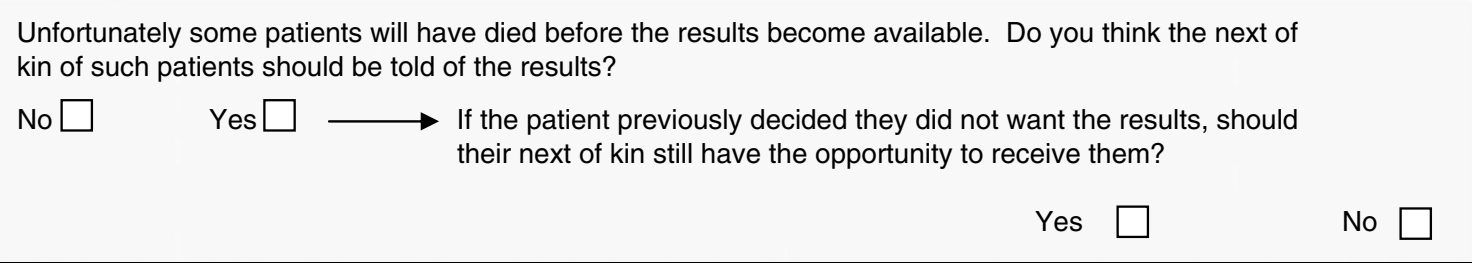

Figure 2 Health Care Professional Questionnaire. 
trials office, should in future hold addresses so they could send results directly to patients' homes. HCPs were encouraged to circulate the questionnaire to all appropriate staff directly involved in the TACT trial, therefore the precise number distributed is not known.

\section{RESULTS}

\section{Providing results to patients}

Patients' views In all, 37\% (1431) of the UK TACT trial population who remained alive at the time the questionnaire was distributed completed and returned it (Table 1). Of those who responded, $30(2 \%)$ patients stated that they did not want trial results, and $6(<1 \%)$ did not answer this question (Table 2). A total of 612 patients ( $44 \%$ of the 1395 who wanted results) thought that for future trials, communication of results to patients should come directly from ICR-CTSU. There was no significant difference in age distribution $(P=0.35)$ nor in current country of residence $(P=0.5)$ between those who would like to have the trial results and those who do not (data not shown). No association was found between preferred method of delivery and age group $(P=0.34)$, nor between preferred method of delivery and UK country of residence $(P=0.55)$. The distribution between age groups and UK country is shown in Table 1.

Health care professionals' views In all $176 \mathrm{HCPs}$ responses came from $89(86 \%)$ participating UK centres, of which 93 $(53 \%)$ were nurses, $80(45 \%)$ clinicians, and three $(2 \%)$ did not specify (Table 2). Among HCPs there was a clear preference for communicating the results in the clinic $(41 \%)$, with no difference between clinicians and nurses $(P=0.18)$. as to which of the three methods of communicating results they preferred; however, the difference in response between HCPs and patients is significant $(P<0.001)$.

Despite knowing that patient addresses are not held by ICR-CTSU, $28(16 \%)$ thought that communication of results to patients should come directly from ICR-CTSU (Table 2).

\section{Providing results to next of kin of deceased patients}

A total of $61 \%$ (868) patients thought that the next of kin of patients who had died should receive trial results, compared with only 27\% (47) HCPs. However, of those who held this view, the proportion who also thought the results should be conveyed to the next of kin of patients who had not wanted the results was very similar for patients and HCPs (60 and 57\% respectively) (Figure 3 ).

\section{DISCUSSION}

Although the response rate of $37 \%$ was higher than anticipated, we cannot assume the results are representative of the views of 2411 patients who were not given the questionnaire or chose not to

Table I Distribution of age groups and UK country of patients responding to questionnaires

\begin{tabular}{lccc}
\hline UK country & $\begin{array}{c}\text { Number (\%) } \\
\text { of patients }\end{array}$ & $\begin{array}{c}\text { Age } \\
\text { group }\end{array}$ & $\begin{array}{c}\text { Number (\%) } \\
\text { of patients }\end{array}$ \\
\hline England & $1140(80)$ & $18-39$ & $106(7)$ \\
Scotland & $102(7)$ & $40-59$ & $1090(76)$ \\
Wales & $92(6)$ & $60-69$ & $217(15)$ \\
N Ireland & $28(2)$ & $70+$ & $15(1)$ \\
Not specified & $69(5)$ & & $3(<1)$ \\
Total & $1431(100)$ & & $1431(100)$ \\
\hline
\end{tabular}

return it. For those who did not reply, we do not know how many did not want results, or did not feel strongly enough to complete and return it. That 30 patients ( $2 \%$ of respondents) felt strongly enough about not receiving the results to return the completed questionnaire highlights the need to ask patients if they want results prior to them being distributed.

Unlike trials testing ongoing treatment for a chronic disease, results of most trials of adjuvant cancer treatment have no impact on future care of participants, nor do they provide information about the future implications of trial treatment for individuals. It is commonplace within adjuvant cancer trials for the collection of long-term follow-up data to continue and the dissemination of trial results to patients could (hypothetically) introduce bias and jeopardise future knowledge and long term outcome data,

Table 2 Patient and HCP preferences for distributing results to patients

\begin{tabular}{|c|c|c|}
\hline Trial results & $\begin{array}{c}\text { Patients (\%) } \\
(n=143 I)\end{array}$ & $\begin{array}{c}\text { HCPs (\%) } \\
(n=176)\end{array}$ \\
\hline Want results in lay terms (for patients) & $1395(97)$ & $169(96)$ \\
\hline Do not want (patients to receive) results & $30(2)$ & $5(3)$ \\
\hline Did not answer & $6(<1)$ & $2(1)$ \\
\hline Method of distribution preferred & $\begin{array}{l}\text { Patients (\%) } \\
(n=1395)\end{array}$ & $\begin{array}{l}\text { HCPs (\%) } \\
(n=169)\end{array}$ \\
\hline Posted to patients when available & $664(47)$ & $32(19)$ \\
\hline By patient's hospital & $140(21)$ & $20(62)$ \\
\hline By ICR-CTSU & $521(79)$ & $12(38)$ \\
\hline Did not answer & $3(<1)$ & - \\
\hline $\begin{array}{l}\text { Letter to say results are available, with national } \\
\text { helpline number to request a copy }\end{array}$ & $177(13)$ & $64(38)$ \\
\hline By patient's hospital & $86(49)$ & $48(75)$ \\
\hline By ICR-CTSU & $91(51)$ & $16(25)$ \\
\hline Results given to patients by clinician or nurse & $554(40)$ & $70(4 \mid)$ \\
\hline At next hospital visit & - & $65(93)$ \\
\hline $\begin{array}{l}\text { Patients recalled for appointment to discuss } \\
\text { results }\end{array}$ & - & $5(7)$ \\
\hline Did not express any preference & - & $3(2)$ \\
\hline
\end{tabular}

Both patients and Health Care Professionals (HCPs) were asked:

$\begin{array}{ll}\text { Do you think the next of } & \text { If the patient previously } \\ \text { kin of such patients } & \text { decided they did not want the } \\ \text { should be told of the } & \text { results, should their next of } \\ \text { results? } & \text { kin receive them? }\end{array}$
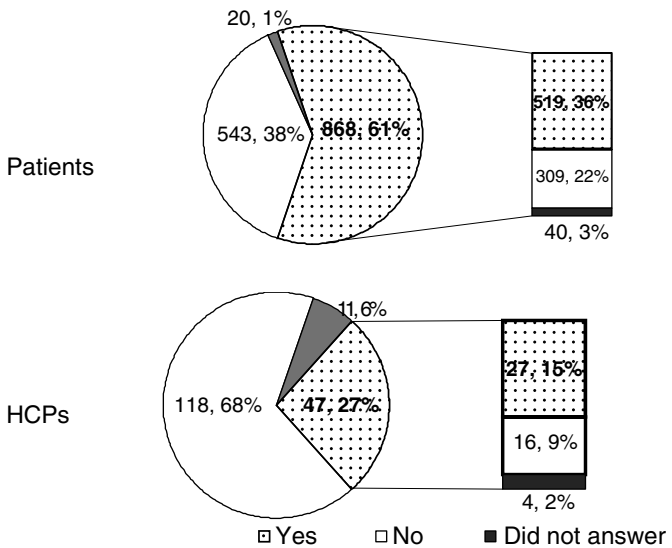

Figure 3 Distributing results to next of kin of deceased patients. 
particularly long-term data on quality of life. This risk, however small, needs to be balanced against the knowledge that the broad scientific trial results will only provide information about an average treatment effect of the experimental $v s$ control treatment in one single trial, which should be viewed in the context of the worldwide evidence.

It is difficult for trial participants to foresee how they will react to receiving the results. For example, in a trial showing a small difference between two treatment arms, approximately $50 \%$ of patients will have received treatment, which was, on average, 'inferior'. However, it may not be inferior for most patients who received it. In addition, highlighting the importance of clear patient information at trial entry about the uncertainty of treatment superiority, raises the question of how to explain to patients that 'inferior' in the trial does not necessarily mean 'inferior' for them, personally.

A single trial is unlikely to provide a definitive answer to the original research question; for patients in the TACT trial an unbiased account of the results would require researchers to explain them within the context of a systematic overview of the emerging worldwide data on taxanes. Added to that are the uncertainties of confidence intervals and the caveat that any promising subgroup analyses are hypothesis generating, not results in themselves. Thus trial results written in lay terms will not only fail to provide the personalised interpretation that patients may want, but if delivered without due consideration to the timing of any relapse a patient may have experienced, or without consideration of the method of distribution, there is a risk they could unnecessary heighten concerns about long-term prognosis and future clinical care.

To avoid unnecessary distress, information that accompanied this survey did not explain that results depended on enough patients relapsing or dying, yet it is this that allows statistically reliable and precise comparisons between treatment groups. Without this knowledge, can patients know whether they would want the results if they had relapsed? Patient response to receiving results could be further complicated by knowing they had also received the 'inferior' treatment. The timing of this questionnaire was such that very few patients had relapsed. If those few patients were excluded from receiving the questionnaire, the views of patients who have relapsed may be under-represented.

Patients were very divided on whether the next of kin of deceased patients should be given trial results, and HCPs erred towards thinking next of kin should not receive results. Qualifying comments made on questionnaires suggest this was a difficult ethical question.

The majority of patients opting to receive results by post expressed a preference for ICR-CTSU to collect patients' addresses for future trials, bypassing the hospital to convey results to patients as soon as they are available; an option that suggests a higher priority for speed than confidentiality of personal data. The responses from HCPs suggest an expectation that trial results need to be interpreted for individual patients. The lower priority given to alacrity could also suggest an awareness that peer-reviewed journals do not allow widespread dissemination of results prior to publication. In addition, results of high profile trials often fall under the media spotlight ahead of any adequate peer review. Dissemination of results by the media and the 'spin' put on them in the popular press may be misinterpreted by trial participants, with HCPs left to interpret results in a way that seems to patients to be less attractive.

\section{ACKNOWLEDGEMENTS}

The hospital staff who distributed patients questionnaires and completed HCP questionnaires, the patients who returned completed questionnaires, David Cameron for his help and guidance, and Antonia Ridolfi for statistical analyses. The Taxotere as Adjuvant Chemotherapy trial is funded by Cancer Research UK, with support in the form of unrestricted educational grants from Sanofi Aventis, Pfizer, and Roche.

\section{REFERENCES}

Barrett-Lee P, Ellis P, Bliss J, on behalf of the TACT Trial Management Group (2002) 'Duration of adjuvant chemotherapy; anthracyclines, taxanes and novel agents - more or less'. Clin Oncol 14: 263-266

Dixon-Woods M, Jackson C, Windridge KC, Kenyon S (2006) Receiving a summary of the results of a trial: qualitative study of participants' views. Br Med J 332: 206-210

Fernandez CV, Kodish E, Weijer C (2003) Informing study participants of research results; an ethical imperative. IRB Ethics Hum Res 25: 12 - 19

Partridge AH, Hackett N, Blood E, Gelman R, Joffe S, Bauer-Wu S, Knudsen K, Emmons K, Collyar D, Schilsky RL, Winer EP (2004) Oncology, physician and nurse practices and attitudes regarding offering clinical trial results to study participants. J Natl Cancer Inst 96: 629-632
Partridge AH, Wong JS, Knudsen K, Gelman R, Sampson E, Gadd M, Bishop KL, Harris JK, Winer EP (2005) Offering participants results of a clinical trial: sharing results of a negative study. Lancet 365: 963-964

Richards PM, Ponder M, Pharoah P, Everest S, Mackay J (2003) Issues of consent and feedback in a genetic epidemiological study of women with breast cancer. J Med Ethics 29: 93-96

Royal College of Physicians (1990) Research Involving Patients. London: RCP

Snowdon C, Garcia J, Elbourne D (1998) Reactions of participants to the results of a randomised controlled trial: exploratory study. $\mathrm{Br}$ Med J 317: $21-26$ 